\title{
ANALISIS DAMPAK TEKNOOGI BUDIDAYA JAGUNG TERHADAP TINGKAT PENDAPATAN DAN DISTRIBUSI PENDAPATAN PETANI JAGUNG PADA KAWASAN USAHA AGRIBISNIS TERPADU (KUAT) DI RASAU JAYA KOMPLEK
}

\author{
NUR FAJAR FEBTYSIANA ${ }^{1)}$, ERLINDA YURISINTHAE ${ }^{2}$, \\ ADI SUYATNO ${ }^{2)}$
}

\author{
${ }^{1}$ Alumni Magister Manajemen Agribisnis Fakultas Pertanian \\ Universitas Tanjungpura Pontianak \\ ${ }^{2}$ Staf Pengajar Fakultas Pertanian Universitas Tanjungpura Pontianak
}

\begin{abstract}
The purpose of the study is (1) To determine the impact of maize cultivation technology to the level of income of corn farmers who use technology ( adopter ) and that do not use ( non- adopters ). (2) To determine the impact of maize cultivation technology on income distribution of farmers who are using technology ( adopter ) and which does not use the ( non- adopters ). Sampling is done by simple random sampling method in each category maisng adopter and non- adopter. The analytical tools used in this research is the analysis of different test $t$ Calculate Income and Income Distribution Analysis by the Gini coefficient based on ( Gini Ratio ), and Lorenz curve. The results showed that the overall average cash income of farmers are using the technology of cultivation ( adopter ) is greater than the average cash income of farmers who do not use the technology of cultivation ( non-adopters ). From the statistical result obtained t value less than or equal to $t$ table $(\mathrm{t} \leq \mathrm{t}$ hits the table $)$ at the $\mathrm{db}=\mathrm{n} 1+\mathrm{n} 2-2$. This suggests that the income level of farmers are using the technology of cultivation ( adopter) did not differ from the level of income of farmers who do not use the technology of cultivation ( non- adopters ). Criteria based on the Gini coefficient ( Gini Ratio ), the Lorenz curve and indicates if the distribution of the income of farmers who do not use corn cultivation technology ( non- adopters ) is more evenly distributed than the income of farmers who do not use the technology of cultivation ( nonadopters ). This suggests that the impact on the use of technology in higher levels of inequality .
\end{abstract}

Keywords : Technology Impact , Income , Income Distribution , Region Agribusiness integrated

\section{PENDAHULUAN}

Sektor pertanian merupakan salah satu sektor penting dalam pembangunan perekonomian Indonesia. Terutama dalam penyediaan pangan, penyediaan bahan baku industri, peningkatan ekspor dan divisa Negara, penyediaan kesempatan kerja dan kesempatan berusaha, serta peningkatan pendapatan petani yang ada pada akhirnya untuk menciptakan kesejahteraan bagi masyarakat. Menurut prediksi International Food Policy Research Institute (IFPRI), jagung merupakan salah satu komoditi pertanian yang paling banyak dicari pada tahun 2020.

Penggunaan teknologi baru di bidang pertanian yang menjadi rekomendasi akan menyebabkan perubahan dalam cara berproduksi yang dalam giliran 
selanjutnya juga akan menyebabkan perubahan pendapatan. Masih terdapat petani yang menggunakan teknik budidaya secara tradisional atau konvensional, hal ini tentunya akan menyebabkan ketimpangan produktivitas dan pendapatan usahatani dan mengakibatkan ketimpangan juga pada total pendapatan petani khususnya petani jagung (Kusrini dkk, 2008).

Hernanto (1996), menjelaskan bahwa kegiatan usahatani bertujuan untuk mencapai produksi dibidang pertanian yang pada akhirnya akan dinilai dengan uang yang diperhitungkan dari nilai produksi setelah di kurangi atau memperhitungkan biaya yang telah di keluarkan dan besarnya pendapatan yang akan diperoleh dari suatu kegiatan usahatani tergantung dari beberapa faktor yang mempengaruhinya seperti luas lahan, tingkat produksi, identitas pengusaha, pertanaman, dan efisiensi penggunaan tenaga kerja. Distribusi pendapatan nasional mencerminkan merata atau timpangnya pembagian hasil pembangunan suatu Negara di kalangan penduduknya, (Dumairy, 1997). Pemahaman mengenai distribusi pendapatan sangat penting, tidak ada artinya jika pertumbuhan ekonomi tinggi dan pendapatan meningkat, namun distribusi pendapatan yang terjadi sangat timpang, dimana masyarakat atau petani kaya yang berjumlah sedikit lebih banyak menikmati kenaikan pendapatan tersebut, sementara masyarakat atau petani miskin yang jumlahnya lebih banyak hanya sedikit mengalami perbaikan pendapatan.

Paket teknologi produksi yang terdiri dari beberapa komponen paket teknologi budidaya jagung seperti penggunaan pupuk yang berimbang, sistem pemeliharaan yang intensif meliputi penyiangan, pembumbunan, PHT dan pengaturan jarak tanam yang tepat. Berpijak dari fakta tersebut adalah penting untuk diukur ketimpangan distribusi pendapatan untuk mengetahui kecendrungan yang sebenarnya mengenai distribusi pendapatan petani jagung di Bintang Mas.

\section{Perumusan Masalah}

Distribusi pendapatan antar petani jagung merupakan masalah yang perlu di ketahui, karena dengan mengetahui distribusi pendapatan antar sesama petani jagung, agar dapat melihat serta menunjukkan hasil dari pemerataan pendapatan yang diperoleh dalam usaha bertani. Dari uraian pada latar berlakang yang ada, maka dapat dirumuskan sebagai berikut :

1. Bagaimana dampak teknologi budidaya jagung di lokasi KUAT terhadap tingkat pendapatan petani jagung yang menggunakan teknologi (adopter) dan petani yang tidak menggunakan (non adopter)?

2. Bagaimana dampak teknologi budidaya jagung di lokasi KUAT terhadap distribusi pendapatan petani yang menggunakan teknologi (adopter)?

\section{Tujuan Penelitian}

Tujuan yang akan dicapai dalam penelitian ini, antara lain :

1. Untuk mengetahui dampak teknologi budidaya jagung terhadap tingkat pendapatan petani jagung yang menggunakan teknologi (adopter) dan petani yang tidak menggunakan (non adopter).

2. Untuk mengetahui dampak teknologi budidaya jagung terhadap distribusi pendapatan petani yang menggunakan teknologi (adopter).

\section{METODOLOGI PENELITIAN}

Penelitian ini dilakukan di wilayah KUAT yang berbasis tanaman jagung khususnya KUAT Rasau Jaya Komplek di Desa Bintang Mas karena merupakan 
wilayah pengembangan tanaman jagung dan memiliki potensi yang cukup luas. Lokasi ini dipilih secara sengaja (purposive) karena merupakan wilayah Kawasan Usaha Agribisnis Terpadu Tanaman jagung lahan gambut.

Penentuan besarnya sampel petani yang diambil, menggunakan teknik penarikan sampel secara sengaja (purposive sample) berdasarkan wilayah, jenis teknologi, adopter dan non adopter. Penentuan besarnya sampel dari suatu populasi dapat dihitung dengan menggunakan rumus Slovin (Sevilla dan Conselo dalam Rahim dan Hastuti, 2007).

Untuk menentukan petani yang akan dijadikan sampel dilakukan dengan metode simple random sampling (cara acak sederhana) pada masing-masing kategori adopter dan non adopter. Pengambilan sampel acak dapat dilakukan dengan cara undian.

Sumber data yang akan digunakan meliputi data primer dan data sekunder. Data yang dikumpulkan mencakup data kualitatif dan kuantitatif dari data primer dan sekunder. Data primer diperoleh dengan melalui survei dengan mewawancarai secara langsung dengan bantuan daftar pertanyaan yang telah disiapkan secara langsung dengan responden. Data sekunder diperoleh dari publikasi lembaga atau instansi yang terkait dan pustaka-pustaka ilmiah lainnya.

Untuk menjawab tingkat pendapatan petani adopter berbeda dari tingkat pendapatan petani non adopterdianalisis dengan menggunakan uji beda rata-rata $(\mathrm{t}$ hitung).

Untuk mengetahui dampak teknologi budidaya jagung terhadap distribusi pendapatan petani yang menggunakan teknologi (adopter) digunakan konsep cara pengukuran menurut Gini Ratio dan Kurva Lorenz. Merujuk dari Todaro dan Smith (2003), untuk menghitung Gini Ratio dapat menggunakan persamaan sebagai berikut:

$G=1-\sum_{i=f}^{k} f_{i}\left(Y_{i}+Y_{i-1}\right)$

Keterangan :

$\mathrm{G}=$ angka Indeks atau Rasio Gini

$\mathrm{k} \quad=$ jumlah kelompok

$f_{\mathrm{i}} \quad=$ proporsi petani dalam kelas $\mathrm{i}$

$\mathrm{Y} i=$ proporsi kumulatif pendapatan tunai dari jumlah petani sampai sampel kelas ke-i dan

$\mathrm{Y}_{\mathrm{i}-1} \quad=$ proporsi kumulatif dari jumlah pendapatan tunai sebelumnya

Tinggi rendahnya tingkat ketimpangan distribusi pendapatan ditentukan indikator sebagai berikut : a) Ketimpangan rendah bila GR $=0,20-0,35$; b) Ketimpangan sedang bila GR $=0,36-0,49$; c) Ketimpangan tinggi bila GR $=0,50$ 0,70. Penentuan tingkat ketimpangan berdasarkan Kurva Lorenz dilihat dari jarak kurva ini ke garis diagonal. Semakin dekat jarak Kurva Lorenz ke garis diagonal (semakin lurus) menyiratkan distribusi pendapatan yang semakin merata. Sebaliknya, jika Kurva Lorenz semakin jauh dari diagonal (semakin melengkung) maka mencerminkan keadaan yang semakin buruk, distribusi pendapatan semakin timpang dan tidak merata. 


\section{HASIL DAN PEMBAHASAN}

\section{Karakteristik Petani Responden}

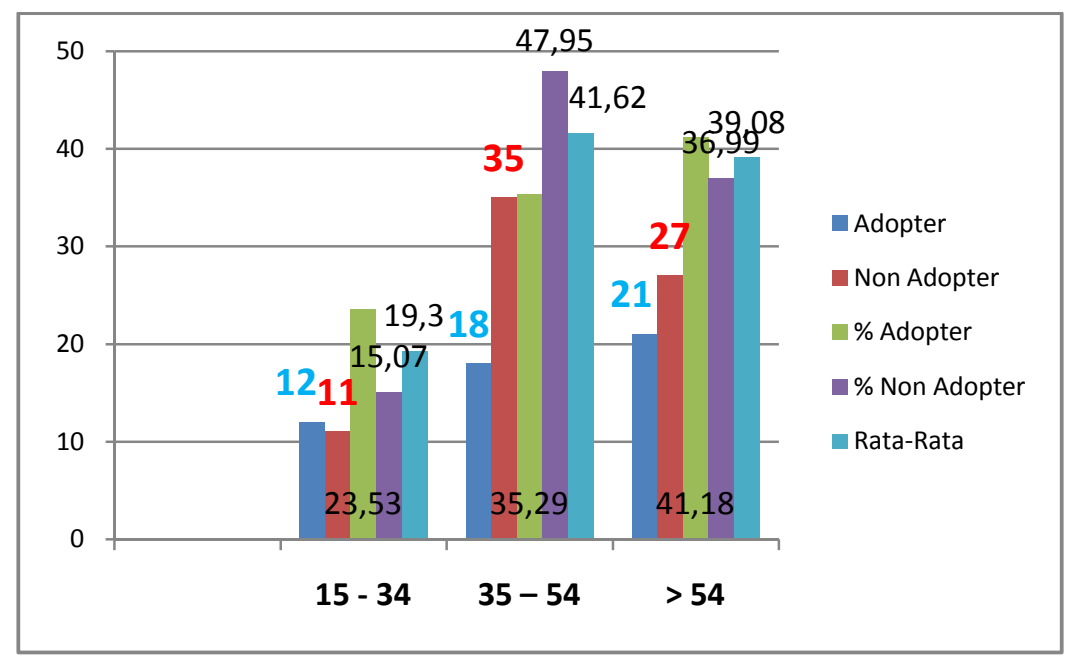

Sumber : Data Diolah Secara Primer (2013)

Grafik 1. Diagram Batang Keadaan Petani Responden Berdasarkan Umur Petani

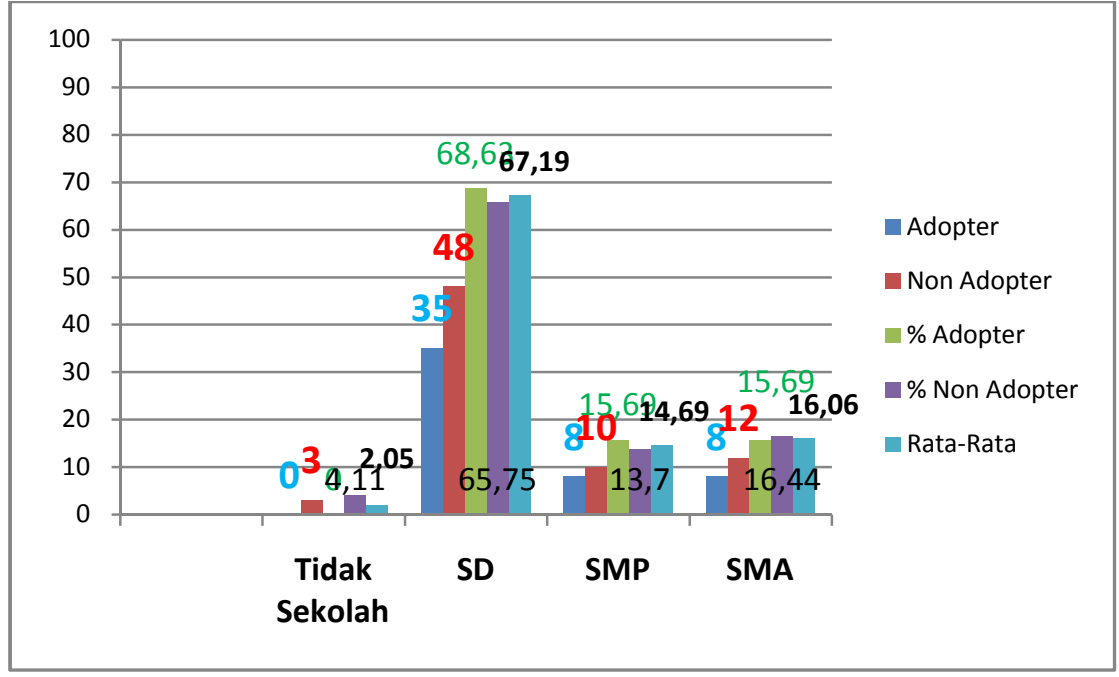

Sumber : Data Diolah Secara Primer (2013)

Grafik 2. Diagram Batang Keadaan Petani Responden Berdasarkan Tingkat Pendidikan 


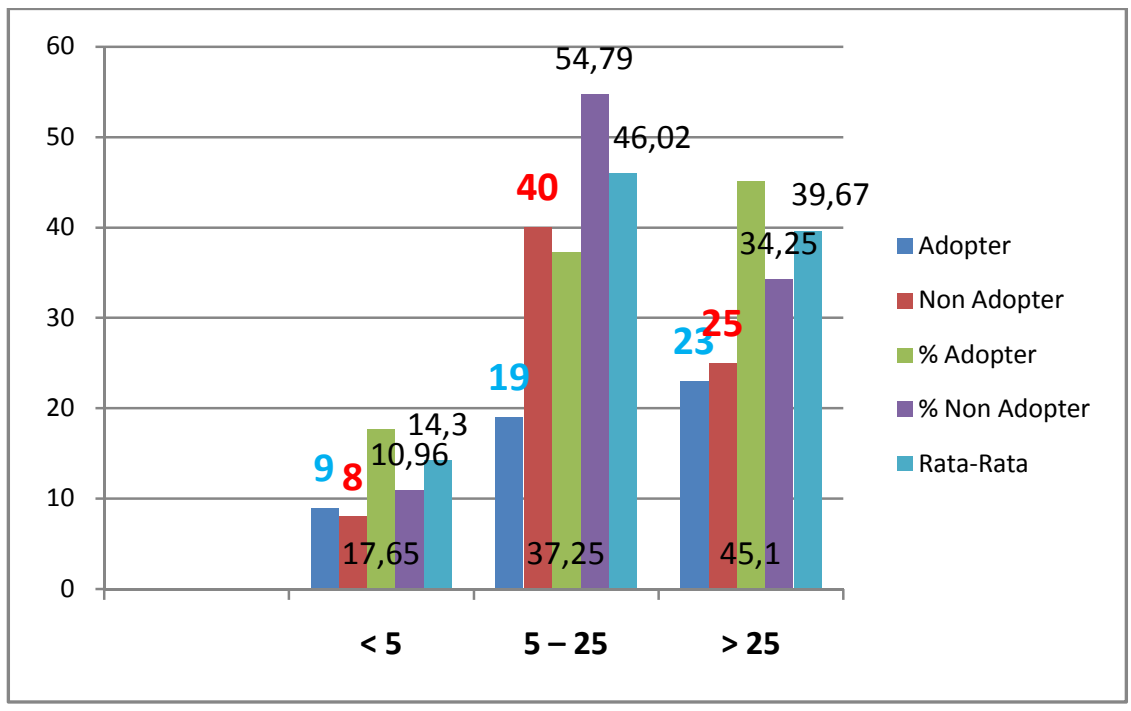

Sumber : Data Diolah Secara Primer (2013)

Grafik 3. Diagram Batang Keadaan Petani Responden Berdasarkan Pengalaman Berusahatani

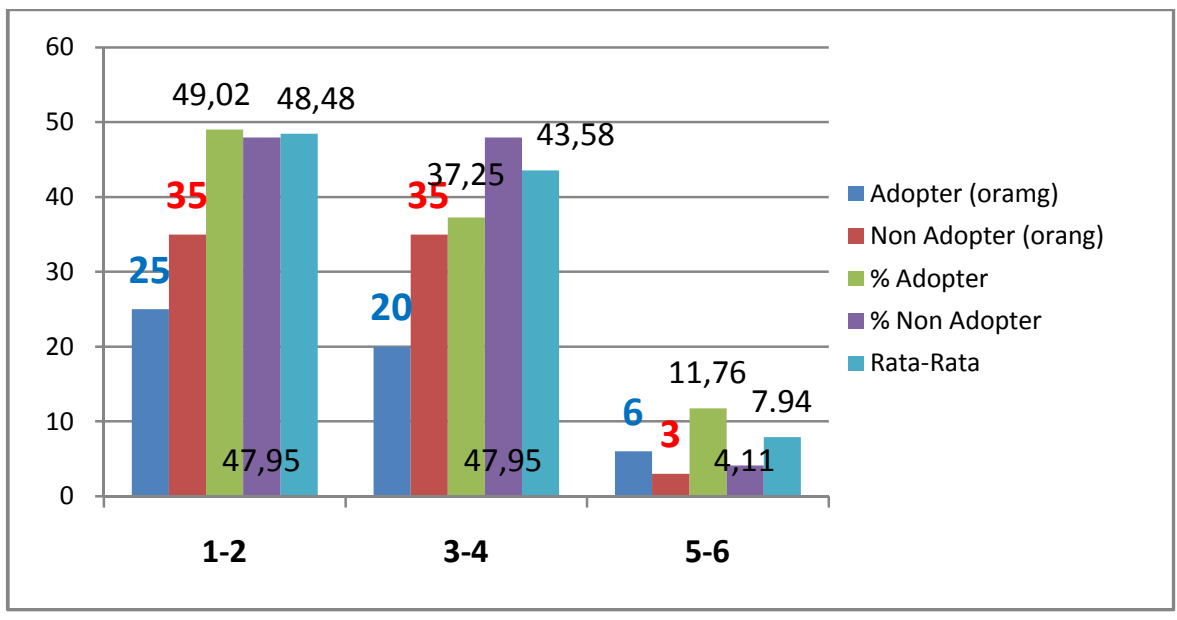

Sumber : Data Diolah Secara Primer (2013)

Grafik 4. Diagram Batang Keadaan Petani Responden Berdasarkan Jumlah Tanggungan Keluarga 


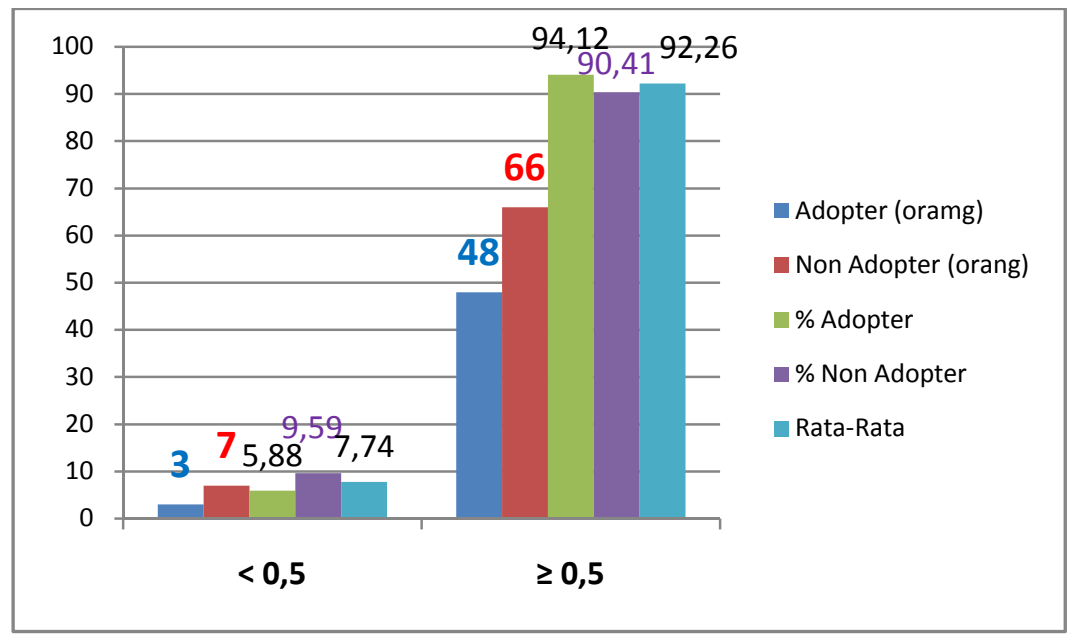

Sumber : Data Diolah Secara Primer (2013)

Grafik 5. Diagram Batang Keadaan Petani Responden Berdasarkan Luas Lahan Garapan

\section{Pendapatan Tunai Usahatani Jagung}

Menurut Soekartawi $d k k$.,(1986), pendapatan tunai usahatani (farm net cash flow) adalah selisih antara penerimaan tunai usahatani (farm receipt) dan pengeluaran tunai usahatani (farm payment). Pendapatan bersih usahatani (net farm income) adalah selisih antara pendapatan kotor (gross farm income) usahatani dan pengeluaran total usahatani (total farm expenses). Penerimaan tunai usahatani (farm receipt) didefinisikan sebagai nilai uang yang diterima dari penjualan produk usahatani. Penerima tunai usahatani tidak mencakup pinjaman uang untuk keperluan usahatani, tidak mencakup yang berbentuk benda dan nilai produk usahatani yang dikonsumsi tidak dihitung. Pengeluaran tunai usahatani (farm payment) didefinisikan sebagai jumlah uang yang dibayarkan untuk pembelian barang jasa bagi usahatani. Dalam analisis usahatani, pendapatan petani digunakan sebagai indikator penting karena merupakan sumber utama dalam mencukupi kebutuhan hidup sehari-hari. Analisis yang digunakan untuk menghitung pendapatan usahatani mengacu pada konsep pendapatan tunai atas biaya yang dikeluarkan yaitu biaya tunai usahatani jagung.

Rata-rata pendapatan tunai per hektar petani adopter dan petani non adopter dan produksi rata-rata petani. Terlihat bahwa secara keseluruhan, rata-rata pendapatan tunai petani adopter lebih besar dibandingkan petani non adopter. Rata-rata Pendapatan tunai petani adopter sebesar Rp. 3.445.174,44/ha sedangkan rata-rata pendapatan tunai petani non adopter Rp. 3.288.445,43/ha.

Hasil uji homogenitas (perbedaan varians) dengan derajat bebas $(\mathrm{db}=\mathrm{n} 1+$ n2-2) tidak terdapat perbedaan varians data (equal varians). Dari hasil uji t secara statistik Ho diterima artinya tingkat pendapatan petani adopter tidak berbeda dari tingkat pendapatan petani non adopter.

Tingkat rata-rata pendapatan tunai petani adopter nilainya lebih tinggi dibandingkan rata-rata pendapatan tunai petani non adopter tetapi perbedaan tersebut tidak signifikan secara statistik. Tidak berbedanya rata-rata pendapatan tunai antara petani adopter dengan petani non adopter disebabkan oleh tiga sebab yaitu produksi, harga jual dan biaya tunai produksi. 
Tabel 1. Analisis Usahatani Petani Adopter dan Petani Non Adopter Desa Bintang Mas

\begin{tabular}{lrr}
\hline \multicolumn{1}{c}{ Uraian } & Petani Adopter & Petani Non Adopter \\
\hline Biaya Sarana Produksi : & & \\
Benih (kg) & $546,411.18$ & $85,989.73$ \\
Urea (kg) & $806,594.77$ & $646,187.21$ \\
NPK (kg) & $614,901.96$ & $334,054.79$ \\
Pupuk Cair (lt) & $171,921.57$ & $61.004,57$ \\
PUKAN (kg) & $419,413,79$ & $327,671.23$ \\
Kapur (kg) & $270,169.93$ & $232,328.77$ \\
Pestisida (lt) & $112,980.39$ & $136,382.65$ \\
Biaya TKLK & $130,857.84$ & $72,271.69$ \\
Biaya Pemipilan & $253,955.29$ & $203,353.42$ \\
Total Biaya UT & $\mathbf{3 , 3 2 6 , 9 6 6 . 7 3}$ & $\mathbf{2 , 0 9 9 , 2 4 4 . 0 6}$ \\
Produksi (kg) & $2,116.29$ & $1,683.65$ \\
Harga (Rp/kg) & 3.200 & 3.200 \\
Penerimaan UT & $\mathbf{6 , 7 7 2 , 1 4 1 . 1 8}$ & $\mathbf{5 . 3 8 7 , 6 8 9 . 5 0}$ \\
Pendapatan UT & $\mathbf{3 , 4 4 5 , 1 7 4 . 4 4}$ & $\mathbf{3 , 2 8 8 , 4 4 5 . 4 3}$ \\
\hline (Sumber: Data Primer & &
\end{tabular}

(Sumber : Data Primer 2013)

Produksi jagung petani adopter lebih tinggi dibandingkan produksi jagung petani non adopter. Potensi rata-rata produksi optimal jagung varietas hibrida $8.900 \mathrm{~kg} / \mathrm{ha}$ sedangkan pada kenyataannya rata-rata produksi yang dicapai hanya $2.116,29 \mathrm{~kg} / \mathrm{ha}$. Rata-rata produksi petani non adopter 1.683,65 kg/ha. Meskipun selisih rata-rata produksi antara petani adopter dan petani non adopter cukup besar yaitu $432,64 \mathrm{~kg} / \mathrm{ha}$, tetapi selisih rata-rata pendapatan tunai antara keduanya sangat kecil hanya sebesar Rp. 156.729,01/ha.

Walaupun pupuk yang digunakan sudah lengkap tetapi ukuran yang digunakan masih belum sesuai dengan rekomendasi. Varietas hibrida (adopter) mempunyai karakteristik yang respon terhadap pemupukan dan rentan terhadap kondisi iklim, karena pada saat penelitian kondisi iklim tidak menentu seperti hujan lebat dan angin kencang. Dengan penggunaan dosis pupuk yang tidak sesuai dan rentan terhadap kondisi iklim menyebabkan kondisi yang kurang optimum bagi pertumbuhan varietas hibrida (adopter) sehingga hasil produksi masih jauh dari yang diharapkan.

Petani menjual hasil dalam bentuk pipilan kering pada pedagang pengumpul yang datang sendiri ketempat petani. Harga jagung pipilan kering setiap musim berbeda tergantung dari harga jagung pipilan kering nasional tetapi harga yang diterima semua petani sama yaitu sebesarRp. 3.200,-/kg. Biaya pemipilan diperoleh dengan mengalikan kuantitas produksi pipilan kering di kalikan upah pipil sebesar Rp 120,- / kg pipilan kering dan Alat pemipilan tersedia dimasingmasing kelompok tani.

Biaya sarana produksi berupa pupuk dan pestisida diperoleh dengan mengalikan kuantitas input produksi yang digunakan petani dengan harga jual input. Untuk biaya tenaga kerja diperoleh dengan mengalikan curahan tenaga kerja dengan upah yang berlaku saat itu yaitu upah tenaga kerja pria sebesar Rp. 25.000,- per hari. Untuk biaya Pengangkutan tidak semua petani membayar tenaga kerja untuk mengangkut hasil jagung pipilan kering. Karena pengangkutan biasanya dilakukan oleh petani itu sendiri dan kalaupun dihitung akan langsung dijadikan upah tenaga kerja luar keluarga. 
Total rata-rata biaya tunai yang dikeluarkan oleh petani adopter lebih besar dibandingkan petani non adopter. Terutama penggunaan biaya untuk pembelian komponen biaya sarana produksi terutama biaya benih dan pupuk. Pengeluaran yang lain berupa pupuk, jumlah pupuk yang digunakan pada petani varietas hibrida (adopter) relatif lebih banyak dibandingkan varietas lokal (non adopter) sehingga biaya yang dikeluarkan juga lebih besar walaupun jumlah pupuk yang diberikan masih belum memenuhi rekomendasi yang seharusnya, akibatnya tidak mampu mencapai potensi rata-rata produksi jagung yang optimal. Sehingga pada akhirnya petani adopter jagung yang digunakan tidak berdampak baik untuk meningkatkan jumlah pendapatan yang diterima petani jagung Desa Bintang Mas.

\section{Distribusi Pendapatan Tunai Petani Jagung}

\section{Nilai Koefisien Gini (Gini Ratio) dan Kurva Lorenz}

Pada dasarnya distribusi pendapatan merupakan kemerataan kemakmuran masyarakat suatu wilayah. Hasil dari perhitungan dengan menggunakan kriteria nilai koefisien Gini (Gini Ratio) dan kurva Lorenz, berdasarkan kriteria Todaro dan Smith (2003), bahwa petani adopter mempunyai tingkat ketimpangan sedang dan petani non adopter mempunyai tingkat ketimpangan pendapatan rendah

Kriteria Nilai koefisien Gini (Gini Ratio) petani yang tidak menggunakan teknologi budidaya (non adopter) lebih rendah $(0,22)$ dibanding petani yang menggunakan teknologi budidaya (adopter) $(0,36)$. Hal ini menunjukkan bahwa penggunaan teknologi berdampak pada tingkat kesenjangan yang lebih tinggi. Dengan menggunakan kurva Lorenz. Terlihat bahwa distribusi pendapatan petani yang tidak menggunakan teknologi lebih mendekati garis merata. Menunjukkan bahwa distribusi pendapatan petani yang tidak menggunakan teknologi lebih merata dibandingkan petani yang menggunakan teknologi jagung, sesuai dengan perhitungan berdasarkan koefisien Gini (Gini Ratio).

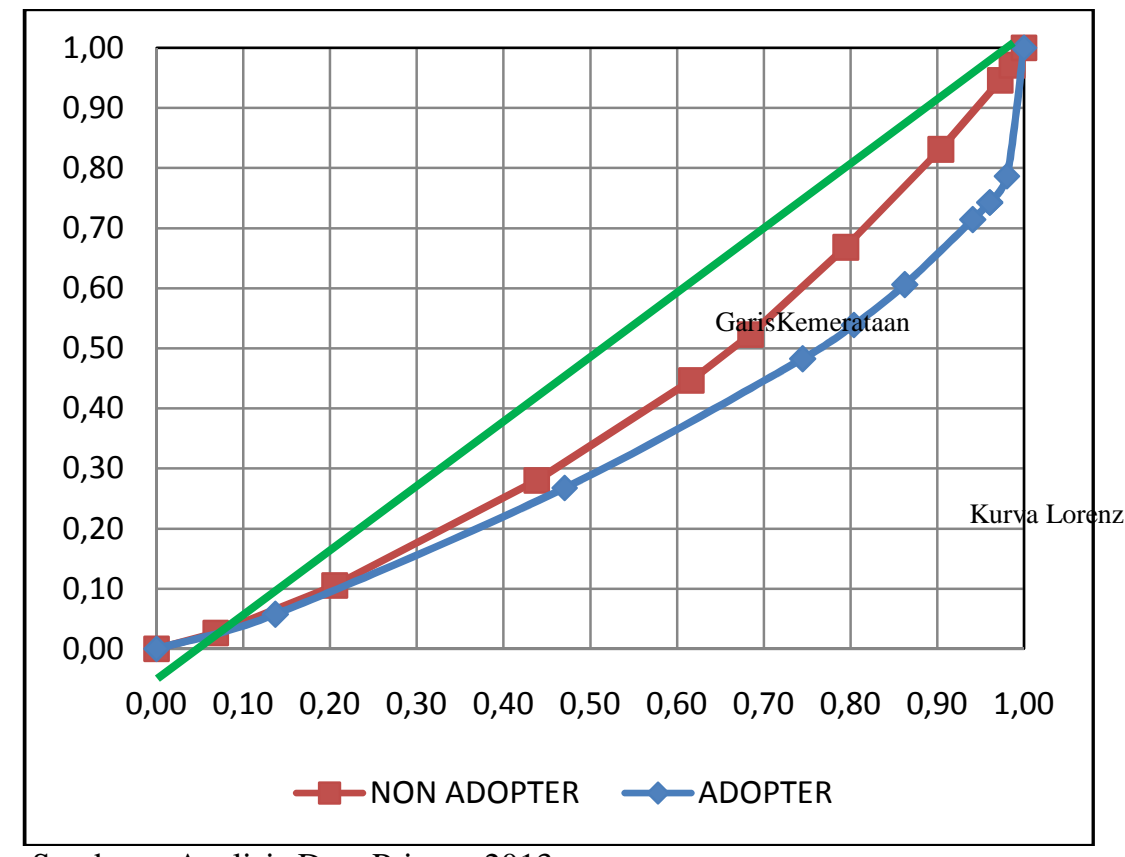

Sumber : Analisis Data Primer, 2013

Grafik 6. Grafik Kurva Lorenz Distribusi Pendapatan Adopter dan Non Adopter 
Masih adanya petani jagung yang tidak menggunakan teknologi budidaya mencerminkan jika petani belum percaya kalau usahatani jagung yang menggunakan teknologi sangat menguntungkan untuk diusahakan. Hal ini disebabkan harga jual jagung yang tidak berbeda dipasaran walaupun sarana produksi yang digunakan biayanya tinggi tetapi jika sepadan dengan pendapatan yang diterima tentunya petani akan lebih tertarik untuk menggunakan teknologi tersebut, sehingga petani non adopter akan berpindah menjadi petani adopter. Selain itu harga jual benih hibrida yang tinggi, banyaknya jumlah sarana produksi yang digunakan penyebab keengganan petani non adopter untuk berpindah bertanam jagung unggul (adopter).

\section{KESIMPULAN}

Tingkat rata-rata pendapatan tunai petani adopter nilainya lebih tinggi dari rata-rata pendapatan tunai dari petani non adopter. Secara statistik tingkat ratarata pendapatan tunai petani adopter tidak berbeda dengan tingkat rata-rata pendapatan tunai petani non adopter.

Kriteria Nilai koefisien Gini (Gini Ratio) petani non adopter lebih rendah dibandingkan petani adopter. Hal ini berarti menunjukkan penggunaan teknologi berdampak pada tingkat kesenjangan tinggi.

Dengan menggunakan kurva Lorenz diperoleh bahwa distribusi pendapatan petani non adopter lebih merata dibandingkan petani non adopter, sesuai dengan perhitungan berdasarkan koefisien Gini (Gini Ratio).

\section{SARAN}

Masih adanya petani jagung yang tidak menggunakan teknologi budidaya mencerminkan jika petani belum percaya kalau usahatani jagung yang menggunakan teknologi sangat menguntungkan untuk diusahakan, salah satu penyebabnya harga jagung dipasaran tidak berbeda. Kedepannya diharapkan pemerintah dapat meningkatkan harga jagung sehingga petani akan tergerak untuk menggunakan teknologi budidaya jagung.

Perlu adanya kerjasama dan koordinasi yang baik antar Instansi dalam pemerintah maupun pemerintah dengan pelaku usaha dan masyarakat petani dalam pengembangan kawasan KUAT sehingga informasi-informasi terbaru dapat diterima dengan baik dan tujuan-tujuan yang diharapkan dapat tercapai.

Kebijakan-kebijakan yang diambil oleh pemerintan pusat maupun daerah perlu adanya proses monitoring dan evaluasi dengan melibatkan pihak-pihak yang berkompeten seperti melibatkan perguruan tinggi, lembaga swadaya masyarakat yang berintegritas dan masyarakat petani itu sendiri. Sehingga kebijakankebijakan tersebut menjadi contoh atau pembelajaran dikemudian hari.

Perlu kajian lebih lanjut mengenai dampak teknologi seperti dampak teknologi terhadap tingkat pendapatan rumah tangga petani dan distribusi pendapatan rumah tanggah petani. 


\section{DAFTAR PUSTAKA}

Dumairy, 1997. Perekonomian Indonesia. Penerbit Erlangga. Jakarta.

Kusrini, N., Dwidjono, H.D. dan Jamhari. Dampak Penggunaan Varietas Unggul Terhadap Distribusi Pendapatan Petani Jagunf di Kalimantan Barat dalam http://www.ISJD.pdi.lipi.go.id/jurnal diakses Pada Tanggal 30 Maret 2012 Pukul 15.28 WIB.

Kuznet, S. 1933. National Income In The American Ecinomic Associztion 1955 Reading In The Theory of Income Distribution. Philadelphia. The Blakston Company.

Rahim, A dan Hastuti. 2007. Pengantar Teori dan kasus Ekonomika Pertanian. Penebar Swadaya. Jakarta.

Todaro, M.P., dan Smith, S.C. 2006. Pembangunan Ekonomi di Dunia Ketiga. Penerbit Erlangga. Jakarta.

Hernanto, Fadholi. 1996. Ilmu Usahatani. Penebar Swadaya. Jakarta.

Soekartawi, Soehardo, Dillon dan Handaker. 1986. Ilmu Usaha Tani dan Penelitian Untuk Pengembangan Petani Kecil. U-J Press. Jakarta. 